\title{
A probabilistic approach to assessment of the quality of drinking water
}

\author{
Katarzyna Wątor*, Ewa Kmiecik, Adam Postawa, Piotr Rusiniak \\ AGH University of Science and Technology, Faculty of Geology, Geophysics and Environmental Protection, \\ Department of Hydrogeology and Engineering Geology, Mickiewicza 30 Avenue, 30-059 Kraków, Poland \\ *corresponding author, e-mail: katarzyna.wator@agh.edu.pl
}

\begin{abstract}
Knowledge of uncertainty in analytical results is of prime importance in assessments of compliance with requirements set out for the quality of water intended for human consumption. Assessments of drinking water quality can be performed using either a deterministic or a probabilistic method. In the former approach, every single result is referred directly to the parametric value, while in the probabilistic method uncertainty related to analytical results is taken into account during the decision-making process. In the present research, laboratory uncertainty and uncertainty determined on the basis of results of analyses of duplicate samples collected in two Polish cities were compared and used in the probabilistic approach of water quality assessment. Using the probabilistic method, more results were considered to be "above the parametric value". Most excesses were observed when the maximum allowable uncertainty as set out in the Regulation of the Minister of Health of 7 December 2017 was used, which is due to the highest values of these uncertainties. The lowest values above parametric values in the probabilistic approach were observed when measurement uncertainty was considered.
\end{abstract}

Key words: QA/QC, water intended for human consumption, heavy metals, uncertainty, decision rules

\section{Introduction}

In Polish regulations, parametric values for 45 physicochemical parameters (among others, $\mathrm{Al}$, As, $\mathrm{Cd}, \mathrm{Cr}, \mathrm{Cu}, \mathrm{Fe}, \mathrm{Mn}, \mathrm{Ni}$ and $\mathrm{Pb}$ ) have been established (RMH, 2017). The maximum permissible levels (MPLs) for these elements are comparable with the requirements of Council Directive 98/83/EC of 3 November 1998 on the quality of water intended for human consumption (EC, 1998). The proposal for a directive of the European Parliament and of the Council on the quality of water intended for human consumption (EC, 2018) recommends maintaining the current parametric value for arsenic, cadmium, copper and nickel. In this document, the Commission proposes to lower the maximum permissible concentration (MPL) of lead to $5 \mu \mathrm{g} / \mathrm{L}$ and reduce the MPL of chromium (especially $\mathrm{Cr}(\mathrm{VI})$ ) to $25 \mu \mathrm{g} / \mathrm{L}$ after a transition period of 10 years following the coming into force of the Directive. WHO guidelines for drinking water established similar parametric values except for cadmium and nickel, for which maximum permissible concentrations are appropriately 3 and $70 \mu \mathrm{g} / \mathrm{L}(\mathrm{WHO}, 2011)$. Both EU and WHO documents did not set out MPLs in case of aluminium, iron and manganese. RMH (2017) also introduced maximum acceptable values of precision, accuracy and uncertainty of methods used during analyses of drinking water. Knowledge of uncertainty arising from sampling and chemical analysis is very important, especially when concentrations of selected parameters are close to MPLs. The assessment of drinking water quality can be performed using either a deterministic or probabil- 
istic method. In the former approach, every single result is referred directly to the parametric value, while in the latter, uncertainty related to the analytical results is taken into account during the decision-making process (Ellison \& Williams, 2007; Demetriades, 2010; Wątor et al., 2016).

The simplest method which probably requires the lowest financial expenses for estimating uncertainty is the duplicate samples method. It can be carried out in accordance with the balanced design or a simplified version of it, the unbalanced design (Garret \& Goss, 1980; Ellison \&Williams, 2007; ISO, 2016a; Wątor et al., 2016; Kmiecik, 2018). Duplicate samples are collected in parallel with normal samples, using the same sampling procedure by the same sampler. Samples are further analysed in the same laboratory, using the same analytical methods and by the same analyst. This allows to minimise systematic errors arising from sampling and analysis, the contribution of which are not included in this method of estimating uncertainty (Ellison \& Williams, 2007; Kmiecik, 2011; Wątor et al., 2016).

The main goal of the present research was a comparison of laboratory uncertainty and uncertainty determined on the basis of results of analyses of duplicate samples collected in two Polish cities.
This makes it possible to assess whether or not the chosen method of sample collection and analysis is appropriate for the purpose of checking the quality of drinking water. Uncertainty estimated were used in probabilistic assessment of drinking water quality.

\section{Material and methods}

Water samples were collected from two different water supply systems. In total, two hundred samples were taken from taps in houses and flats in two Polish cities - Kraków and Myszków. In parallel with one hundred normal samples, eleven duplicates and blanks were collected during each fieldwork. One sampling protocol was used. The first liter of water was taken directly from the tap without prior rinsing of the installation. Concentrations of $\mathrm{Al}, \mathrm{As}, \mathrm{Cd}, \mathrm{Cr}, \mathrm{Cu}, \mathrm{Fe}, \mathrm{Mn}, \mathrm{Ni}$ and $\mathrm{Pb}$ were determined using the ICP-MS method (mass spectrometer ELAN 6100, PerkinElmer) in accordance with requirements described in the ISO (2016b) standard. The samples were analysed in the certified AGHUST Hydrogeochemical Laboratory (certificate of accreditation $A B$ 1050). Limits of quantification and

Table 1. ICP-MS method parameters compared with requirements set out by EC (1998) and RMH (2017)

\begin{tabular}{|c|c|c|c|c|c|}
\hline \multirow[b]{2}{*}{ Parameter } & \multicolumn{2}{|c|}{ ICP-MS method parameters } & \multicolumn{3}{|c|}{ EC (1998) and RMH (2017) requirements } \\
\hline & $\begin{array}{l}\text { Limit of quantification } \\
\text { (LOQ) }[\mu \mathrm{g} / \mathrm{L}]\end{array}$ & $\begin{array}{l}\text { Uncertainty } \\
\left(U_{l a b}\right)[\%]\end{array}$ & $\begin{array}{l}\text { Maximum permissible level } \\
(\mathrm{MPL})[\mu \mathrm{g} / \mathrm{L}]\end{array}$ & $\begin{array}{l}\text { Limit of detection } \\
\quad(\mathrm{LOD})[\mu \mathrm{g} / \mathrm{L}]\end{array}$ & $\begin{array}{l}\text { Uncertainty } \\
\left(U_{R M H}\right)[\%]\end{array}$ \\
\hline $\mathrm{Al}$ & 5 & 14 & 200 & 20 & 25 \\
\hline As & 1 & 18 & 10 & 1 & 30 \\
\hline $\mathrm{Cd}$ & 0.3 & 20 & 5 & 0.5 & 25 \\
\hline $\mathrm{Cr}$ & 5 & 19 & 50 & 5 & 30 \\
\hline $\mathrm{Cu}$ & 1 & 20 & 2000 & 200 & 25 \\
\hline $\mathrm{Fe}$ & 20 & 16 & 200 & 20 & 30 \\
\hline $\mathrm{Mn}$ & 3 & 11 & 50 & 5 & 30 \\
\hline $\mathrm{Ni}$ & 1 & 16 & 20 & 2 & 25 \\
\hline $\mathrm{Pb}$ & 0.1 & 15 & 10 & 1 & 25 \\
\hline
\end{tabular}

Table 2. Measurement uncertainty calculated using ROBAN software

\begin{tabular}{ccccc|}
\hline & \multicolumn{3}{c}{ FIELD-1 } & \multicolumn{2}{c|}{ FIELD-2 } \\
\cline { 2 - 5 } Parameter & $\begin{array}{c}\text { Mean concentration } \\
\left(x_{\text {mean }}\right)[\mu \mathrm{g} / \mathrm{L}]\end{array}$ & $\begin{array}{c}\text { Measurement uncertainty } \\
\left(U_{\text {meas }}\right)[\%]\end{array}$ & $\begin{array}{c}\text { Mean concentration } \\
\left(x_{\text {mean }}\right)[\mu \mathrm{g} / \mathrm{L}]\end{array}$ & $\begin{array}{c}\text { Measurement uncertainty } \\
\left(U_{\text {meas }}\right)[\%]\end{array}$ \\
$\mathrm{Al}$ & 26.89 & 7.67 & 2.76 & 46.59 \\
$\mathrm{As}$ & 0.78 & 6.43 & 0.77 & 9.35 \\
$\mathrm{Cd}$ & 0.34 & 9.91 & 0.44 & 7.31 \\
$\mathrm{Cr}$ & 4.51 & 7.50 & 4.43 & 7.64 \\
$\mathrm{Cu}$ & 23.88 & 2.70 & 7.17 & 3.21 \\
$\mathrm{Fe}$ & 157.9 & 14.97 & 424.8 & 2.63 \\
$\mathrm{Mn}$ & 4.14 & 5.36 & 46.4 & 3.36 \\
$\mathrm{Ni}$ & 2.03 & 3.16 & 1.77 & 8.83 \\
$\mathrm{~Pb}$ & 1.65 & 9.45 & 2.02 & 4.36 \\
\hline
\end{tabular}


uncertainties calculated during method validation were compared with requirements included in regulations set out by the Ministry of Health (RMH, 2017) and Drinking Water Directive (EC, 1998); these can be found in Table 1.

Total uncertainties declared by the laboratory are lower than minimum values of this characteristic of the analysis included in RMH (2017). Also, limits of quantification for the selected elements met requirements of this regulation (Table 2) and are even lower than the maximum permissible detection limit values (Table 1).

\section{Results and discussion}

Precision was expressed as a relative standard deviation of multiple measurements $(n=10)$ of the same sample, whereas accuracy was determined for the natural water samples spiked with the known concentration of analytes. The results obtained were compared with requirements of RMH (2017) (Fig. 1).

In case of precision, the relative standard deviations are significantly lower than permissible values set at a level of $10 \%$. For $\mathrm{Al}, \mathrm{Ni}, \mathrm{Pb}$ and $\mathrm{Zn}$ accuracy is equal to $10 \%$, which is the maximum allowable value according to RMH (2017).

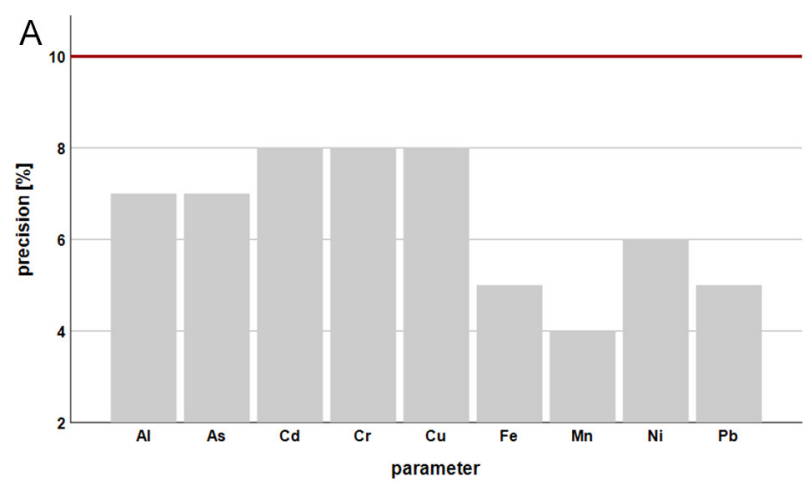

B

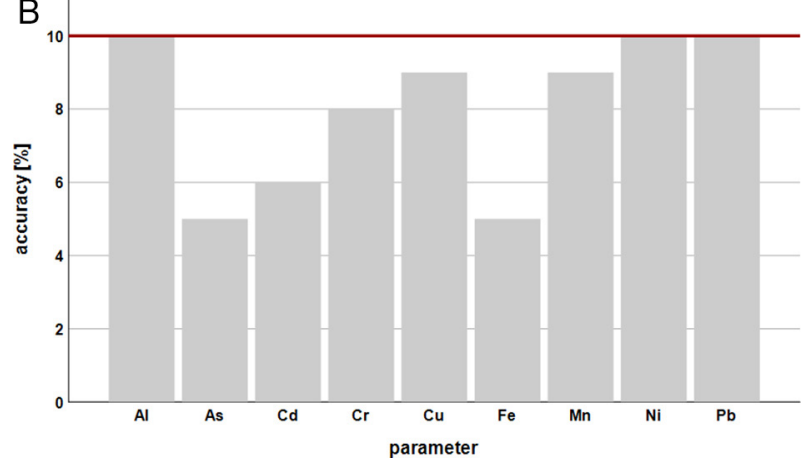

Fig. 1. Results of precision (A) and accuracy (B) determination related to requirements set out by RMH (2017) red line
Duplicates were collected and analysed in the same way as the normal samples. The unbalanced design was applied (Ellison \& Williams, 2007; Kmiecik, 2011).

ROBAN software was used for determination of measurement uncertainties $\left(U_{\text {meas }}\right)$ during both sampling campaigns. Robust ANOVA was chosen as the method of calculation.

The concentrations of selected elements observed (Al in FIELD-2 campaign and $\mathrm{As}$ and $\mathrm{Cr}$ in both fieldwork campaigns) are below laboratory limits of quantification (see Tables 1 and 2). However, because of the comparable concentrations in normal and duplicate samples and acceptable values of precision and accuracy, it can be stated that all data can be included in estimating uncertainties. Such low concentrations of aluminium (about half of the limit of quantification) are reflected in the calculated measurement uncertainty which reached almost $50 \%$ (Table 2). With regard to all other elements analysed during FIELD-1 and FIELD-2 operations, the determined measurement uncertainties are below those declared by the laboratory.

All results obtained during normal samples analyses $(n=100)$ were compared with the maximum permissible concentrations established by the Minister of Health in RMH (2017). Box-and-whiskers plots were used for graphical presentation of the deterministic approach (Fig. 2). In this method, every single result is referred directly to the parametric value. When measured concentrations exceed MPL, water cannot be used for drinking purposes. When the deterministic approach is used to determine compliance with legal requirements, selected points (samples) in both field campaigns where concentrations of iron and lead exceeded maximum permissible levels were indicated. Moreover, results exceeding parametric values were also observed in the case of nickel and manganese in some samples collected during FIELD-2 campaigns (Fig. 2).

The probabilistic method was applied in three variants with 1) uncertainty declared by the laboratory $\left(U_{l a b}\right)$ (Table 1$), 2$ ) measurement uncertainty estimated during QA/QC programme $\left(U_{\text {meas }}\right)$ (Table 2) and 3) maximum allowable uncertainty $\left(U_{R M H}\right)$ according to RMH (2017) (Table 1). The decision rule was defined as follows: water can be used for drinking purposes when the determined concentration, plus the uncertainty, are below the parametric value (Ellison \& Williams, 2007; Demetriades, 2010; Wątor et al., 2016). Figure 3 presents comparisons of these methods for nickel in selected samples for which concentrations were close to the parametric value. 

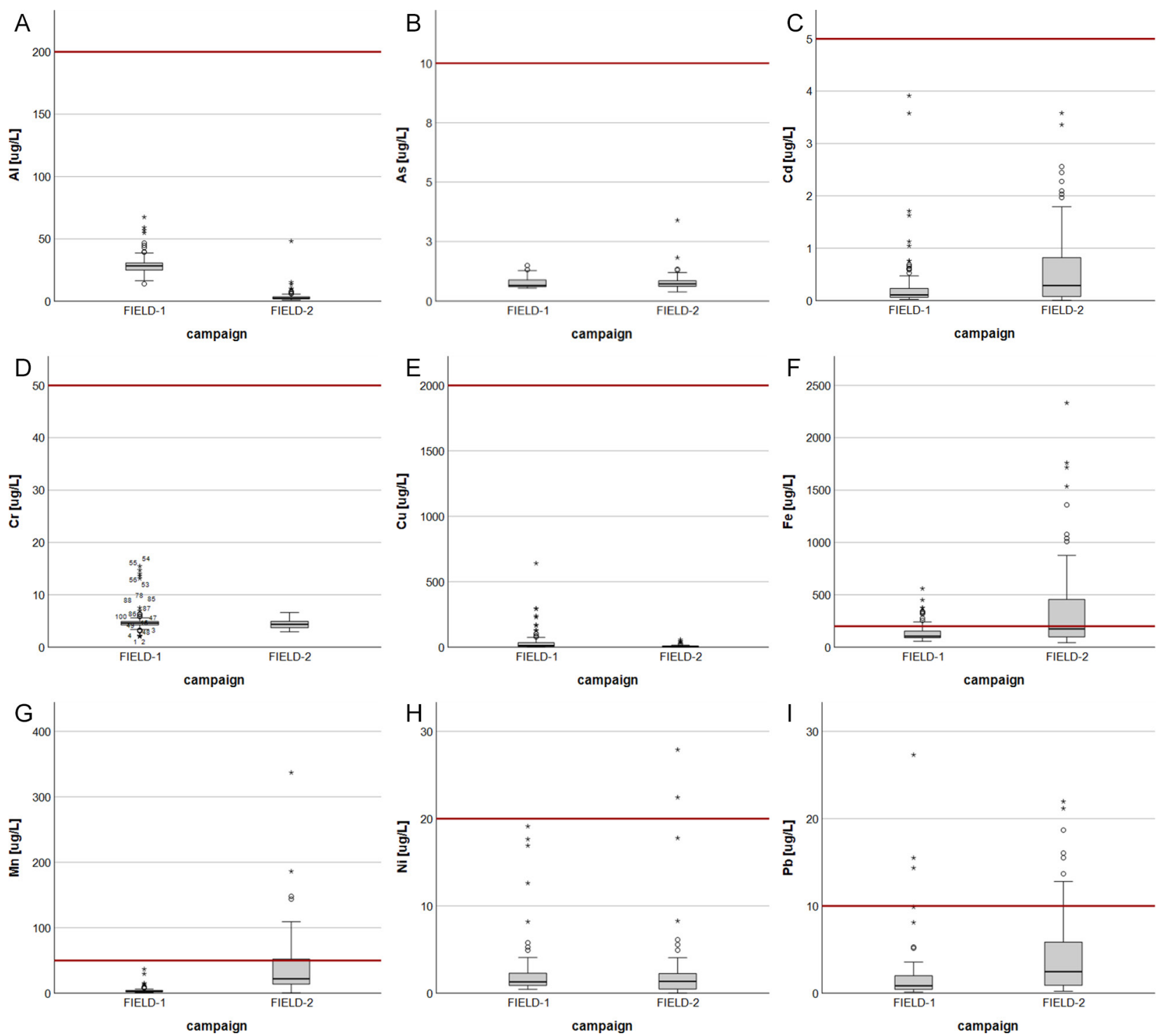

Fig. 2. Results of deterministic approach for $\mathrm{Al}(\mathbf{A}), \mathrm{As}(\mathbf{B}), \mathrm{Cd}(\mathbf{C}), \mathrm{Cr}(\mathbf{D}), \mathrm{Cu}(\mathbf{E}), \mathrm{Fe}(\mathbf{F}), \mathrm{Mn}(\mathrm{G}), \mathrm{Ni}(\mathbf{H})$ and $\mathrm{Pb}(\mathbf{I})$ concentrations, in comparison with MPL values (red line): the thick lines in the centre of boxes represent the median; the top and bottom box lines show the first and third quartiles; the whiskers indicate maximum and minimum values, with exception of outliers (circles) and extremes (asterisks); outliers are at least 1.5 box lengths away from the median, extremes are at least three box lengths

The number of sampling points with concentrations exceeding the maximum permissible level in drinking water in all of above-mentioned approaches are shown in Table 3 . When the decision rule is defined as in the example presented, there is high confidence in a correct acceptance of results. This means that the risk that water with too high concentrations of the elements analysed will be considered as water intended for human consumption is relatively low. The results presented in Table 3 reflect this dependence. Using the probabilistic method of assessment, more results are considered to be "above the parametric value". Most of excesses were observed when the maximum allowable uncertainty set in
RMH (2017) was used, which is due to the highest values of these uncertainties. The lowest number of results above parametric values in the probabilistic approach were observed when measurement uncertainties were considered. Uncertainty estimated on the basis of duplicate samples is usually lower than those declared by the laboratory. In uncertainty estimated during validation or verification of analytical methods, all sources are taken into account and the maximum expected uncertainty usually is referred to results of the analysis. Some systematic errors are minimised by collection of samples by a single sampler, use of the same sampling protocol and performance of analyses in the same laboratory, 

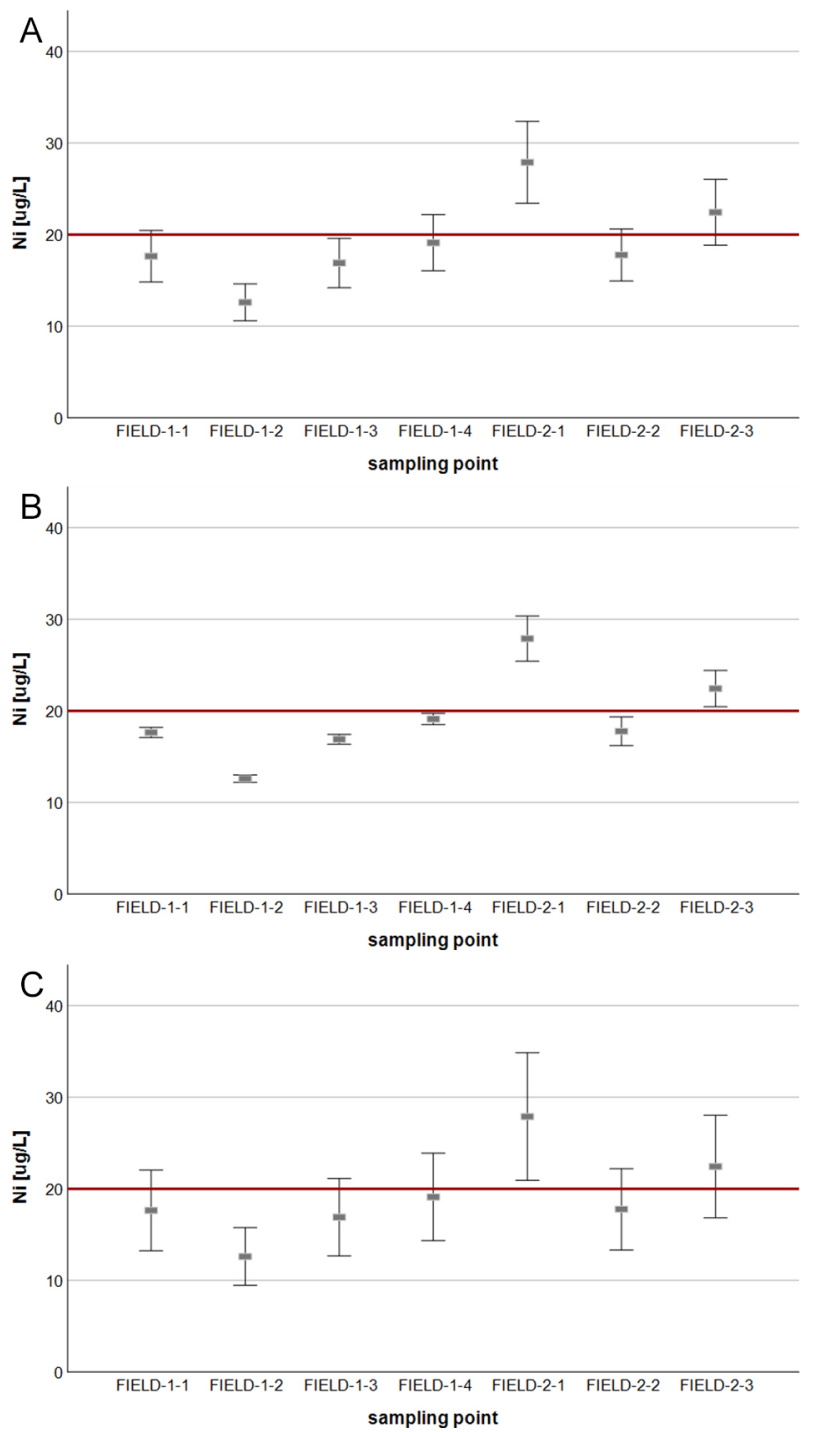

Fig. 3. Probabilistic approach for Ni concentrations in selected samples using: A - Laboratory uncertainty; B - Measurement uncertainty; C - Maximum allowable uncertainty (according to RMH, 2017). Red lines show MPL values using the same analytical method (Ramsey \& Ellison, 2007; Wątor et al., 2016; Rusiniak et al., 2017). In view of the very low concentrations of $\mathrm{Al}, \mathrm{As}, \mathrm{Cd}$, $\mathrm{Cr}$ and $\mathrm{Cu}$, which were definitely below MPL values, any excess was observed in deterministic and all probabilistic approaches alike. Table 3 shows the number of samples with concentrations in excess of MPLs (EC, 1998; RMH, 2017) in deterministic and probabilistic approaches, with different variants of uncertainty estimates for four other elements, viz. $\mathrm{Fe}, \mathrm{Mn}, \mathrm{Ni}$ and $\mathrm{Pb}$.

\section{Conclusions}

Knowledge of uncertainty of analytical results is of crucial importance in assessing compliance with requirements for the quality of water intended for human consumption. Uncertainties estimated on the basis of at least eight duplicate samples (Ramsey \& Ellison, 2007) will allow the end user to make correct decisions and assess the fitness of the results of measurements for the intended purpose. To minimise the risk of incorrect decisions it is necessary to consider the concentrations measured along with uncertainty which include all possible sources. The use of a deterministic approach or an underestimated uncertainty in a probabilistic approach may result in making wrong decisions.

\section{References}

Demetriades, A., 2010. Use of measurement uncertainty in a probabilistic scheme to assess compliance of bottled water with drinking water standards. Journal of Geochemical Exploration 107, 410-422.

EC, 1998. Council Directive 98/83/EC of 3 November 1998 on the quality of water intended for human consumption. Official Journal of the European Communities 330, 1-23.

Table 3. Number of sampling points with concentrations in excess of MPL (EC, 1998; RMH, 2017) in deterministic and probabilistic approaches, with different variants of uncertainty estimates

\begin{tabular}{|c|c|c|c|c|c|c|}
\hline & & & \multicolumn{4}{|c|}{ Parameter } \\
\hline & & & $\mathrm{Fe}$ & $\mathrm{Mn}$ & $\mathrm{Ni}$ & $\mathrm{Pb}$ \\
\hline \multirow[t]{4}{*}{ FIELD-1 } & \multicolumn{2}{|l|}{ Deterministic approach } & 17 & - & - & 2 \\
\hline & \multirow[t]{3}{*}{ Probabilistic approach } & $x+U_{l a b}$ & 22 & - & 2 & 3 \\
\hline & & $x+U_{R M H}$ & 27 & - & 3 & 3 \\
\hline & & $x+U_{\text {meas }}$ & 22 & - & - & 2 \\
\hline \multirow[t]{4}{*}{ FIELD-2 } & \multicolumn{2}{|c|}{ Deterministic approach } & 44 & 26 & 3 & 14 \\
\hline & \multirow[t]{3}{*}{ Probabilistic approach } & $x+U_{l a b}$ & 46 & 31 & 3 & 15 \\
\hline & & $x+U_{R M H}$ & 51 & 37 & 3 & 16 \\
\hline & & $x+U_{\text {meas }}$ & 44 & 29 & 2 & 14 \\
\hline
\end{tabular}


EC, 2018. Proposal for a Directive of the European Parliament and of the Council on the quality of water intended for human consumption (recast). COM/2017/0753 final 2017/0332 (COD).

Ellison, S.L.R. \& Williams, A. (Eds), 2007. Use of uncertainty information in compliance assessment. Eurachem/ CITAC guide.

Garrett, R.G. \& Goss, T.I., 1980. UANOVA: a Fortran IV program for unbalanced nested analysis of variance. Computers \& Geosciences 6, 35-60.

ISO, 2016a. ISO 5667-14: Water quality - Sampling - Part 14: Guidance on quality assurance and quality control of environmental water sampling and handling.

ISO, 2016b. ISO 17294-2: Water quality - Application of inductively coupled plasma mass spectrometry (ICP-MS) Part 2: Determination of selected elements including uranium isotopes.

Kmiecik, E., 2011. Metodyczne aspekty oceny stanu chemicznego wód podziemnych [Methodological aspects of assessing the chemical status of groundwater]. Wydawnictwa AGH 230, 161-172.

Kmiecik, E., 2018. Analytical procedures for ion quantification supporting water treatment processes. [In]: J. Bundschuh \& B. Tomaszewska (Eds): Geothermal water management. CRC Press, 83-112.
Ramsey, M.H. \& Ellison, S.L.R. (Eds), 2007. Measurement uncertainty arising from sampling: A guide to methods and approaches. Eurachem/CITAC Guide, Eurachem.

RMH, 2017. Rozporzadzenie Ministra Zdrowia z dnia 7 grudnia 2017 r. w sprawie jakości wody przeznaczonej do spożycia przez ludzi [Regulation of the Minister of Health on the scope on quality of water intended for human consumption, the Act of 7 December 2017]. Dz.U. 2017 poz. 2294.

Rusiniak, P., Wątor, K. \& Plata, J., 2017. Deterministic and probabilistic approaches to the denomination of the hydrochemical type of potentially medicinal groundwater from the "Zdrój Główny" intake (Krzeszowice, Poland). Geology, Geophysics E Environment 4, 303-309.

Wątor, K., Kmiecik, E. \& Tomaszewska, B., 2016. Assessing medicinal qualities of groundwater from the Busko-Zdrój area (Poland) using the probabilistic method. Environmental Earth Sciences 75, 1-13.

WHO, 2011. Guidelines for drinking-water quality $-4^{\text {th }} \mathrm{ed} .1$. Potable water - standards. 2. Water - standards. 3. Water quality - standards. 4. Guidelines. World Health Organization, Geneva.

Manuscript received: 26 March 2019 Revision accepted: 26 August 2019 